\title{
A quasi-experimental study on a new service option for short-term residential care of older stroke patients
}

This article was published in the following Dove Press journal:

Clinical Interventions in Aging

5 September 2013

Number of times this article has been viewed

\section{Pui-hing Chau' \\ Fannie Yeung ${ }^{2}$ \\ Tsz-wai Chan' \\ Jean Woo ${ }^{2}$}

'School of Nursing, The University of Hong Kong, Hong Kong; ${ }^{2}$ Department of Medicine and Therapeutics, The Chinese University of Hong Kong, Hong Kong
Correspondence: Pui-hing Chau School of Nursing, The University of Hong Kong, 4/F, William MW Mong Block, 2I Sassoon Road, Pokfulam, Hong Kong

$\mathrm{Tel}+85228192626$

Fax +85228726079

Email phchau@graduate.hku.hk
Abstract: We conducted a quasi-experimental study to compare the effectiveness of a new short-term residential care option for stroke rehabilitation with that of usual day hospital care. Primary data were collected from stroke patients and their caregivers from June 2009 to May 2012. New service option users and their caregivers were recruited for the intervention group, while users of usual public geriatric day hospital care and their caregivers were recruited for the control group. The primary outcome measures were Modified Barthel Index (MBI) and MiniMental Status Examination (MMSE) scores. Trained research assistants assessed the outcome measures at the beginning of the rehabilitation program (baseline) and at a 4-month follow-up. Sixty and 128 stroke patients were recruited for the intervention and control groups, respectively; 50 and 105 participants, respectively, completed the 4-month follow-up. At 4-month follow-up, the intervention group had an increased MBI score of 15.3 (95\% confidence interval [CI] 10.8-19.8) and an MMSE score of 1.3 (95\% CI 0.4-2.1). In comparison, the control group had an increased MBI score of 13.3 (95\% CI 9.7-16.8) and an MMSE score of 1.1 (95\% CI 0.4-1.9). Both groups showed a significant improvement in MBI and MMSE scores after 4 months, and there was no significant between-group difference. To conclude, the new service option and the usual care option showed similar improvement in rehabilitation outcomes at 4 months after baseline. Initiatives to provide alternative care options on a user-pay model should be encouraged to ensure a sustainable health care system.

Keywords: rehabilitation, residential care, day hospital, stroke, elderly, Hong Kong

\section{Introduction}

Hong Kong was a British colony up until 1997, when it became a special administrative region of the People's Republic of China. With this historical background, the health care system in Hong Kong is therefore largely modeled after the British system. The British health care system, ie, the National Health Service, is the world's largest publicly funded health care system, and residents can utilize almost all services, particularly general practitioners, free of charge. However, unlike Britain, Hong Kong has a low tax rate that never rises above $15 \%$, so maintaining a universal health care system is not feasible. Consequently, Hong Kong has assigned more of its public resources to tertiary care as opposed to primary care. The Hospital Authority, a statutory body that manages Hong Kong's public hospitals, provides over $90 \%$ of inpatient services, while private physicians in fee-for-service practices provide about $30 \%$ of outpatient services. ${ }^{1}$ The government's fundamental philosophy is that "no one is denied adequate medical care due to lack of means."2 The Hospital Authority provides services at no or very low fees, and has a fee-waiving mechanism. ${ }^{3}$ However, this usually results in long queues for public hospital services. ${ }^{4}$ 
The life expectancy of Hong Kong's population is increasing; however, this poses a potentially higher risk of morbidity and frailty in later life, leading to greater utilization of health care services. Currently, over half of the beds in public hospitals in Hong Kong are occupied by the elderly. ${ }^{5}$ The proportion of Hong Kong's population aged 65 years and above doubled from $6.7 \%$ in 1982 to $13.7 \%$ in $2012 .{ }^{6}$ This will no doubt lead to further overloading of the public health care system. In light of the rapidly aging population, the Hong Kong government is actively investigating health care reform. ${ }^{4}$ One proposal aims to provide more options, with the rationale that when some people opt to use nonpublicly funded health care, the pressure on the public system will be relieved. Thus, public resources can be reserved for those of more limited means. One way to achieve this is to promote user-pay or copayment services in partnership with the private sector and nongovernmental organizations.

Medical care for elderly stroke patients in Hong Kong well illustrates the challenges of the current system. Hong Kong has a higher overall stroke incidence than other developed countries (taking into account the differences in the age composition of the population by age-standardization), and the incidence has been decreasing for ischemic stroke, but not hemorrhagic stroke. ${ }^{7}$ Meanwhile, the mortality rate from stroke has been declining. ${ }^{8}$ With the aging population, the health care burden that stroke patients present will likely increase. Currently, stroke patients admitted to Hong Kong public hospitals usually remain at acute hospitals for a week before transferring to nonacute hospitals for convalescence for an average of 3 weeks. ${ }^{9}, 10$ After discharge, patients visit a geriatric day hospital for rehabilitation for approximately 3 months. Because patients must travel to the day hospital, transportation must be arranged. Stroke patients treated at private hospitals can stay longer but must pay considerably more. Fees for inpatient service in a local public hospital are HK\$100 (US\$13) per day for acute beds and HK\$68 (US\$9) per day for nonacute beds, and fees include daily attendance of doctors, general nursing, core pathology investigations, rehabilitation, and catering. ${ }^{3}$ Here, fees only refers to the charges to the users, but not the total costs of running the services. While fees that service users need to pay are extremely low, the government has to bear the rest (about 97\%) of the costs of running the services. On the other hand, the fees for inpatient service at private hospitals vary from HK $\$ 400$ (US\$51) per day for a general bed to over HK\$980 (US\$126) per day for a first class bed, and the fees for medicines, dressings, and daily attendance fees for doctors have to be billed separately. ${ }^{11}$ Meanwhile, the administrative process makes switching to the public system difficult, and subsequent charges are much higher. When inpatients discharged from private hospitals wish to be followed up by public hospitals after discharge, they have to go through the Hospital Authority clinical system and queue up for outpatient services. In practice, patients referred from private hospitals may be liable for Hospital Authority private fees which are much higher than ordinary fees. Further, rehabilitation care in private hospitals is very limited and unreasonably expensive. In both cases, discharged stroke patients, particularly elderly ones, who are not ready to return home, may end up in old-age homes. Indeed, over one third of home-dwelling stroke patients are reportedly institutionalized upon hospital discharge, and $43 \%$ of stroke patients receive post-discharge rehabilitation at a geriatric day hospital. ${ }^{10}$

In other countries, home-based rehabilitation is used as an alternative to geriatric day hospitals, focusing more on maintaining activities of daily living. ${ }^{12,13}$ However, homebased therapy is limited by a lack of sufficient treatment intensity and a small physical environment. ${ }^{14}$ In Hong Kong, home-based rehabilitation is provided by domiciliary physiotherapists and occupational therapists. Its advantages include saving traveling and undertaking rehabilitation according to the real home environment. At the same time, it faces challenges from the small physical environment and lack of outreach service providers. On the other hand, rehabilitation in conventional long-term care facilities is insufficient ${ }^{15,16}$ and seldom encourages users to return to independent living. ${ }^{17}$ Thus, a service that can provide onsite rehabilitation and residential care, and encourage users to return to independent living, may address the service gap.

In response to the service gap, one nongovernmental organization, aiming to provide more options for stroke patients able to afford user-pay/copayment services, created a short-term residential care service with onsite rehabilitation for elderly stroke patients. Because of sustainability concerns, this option runs on a user-pay model and its fees start from HK $\$ 10,800$ (US\$1,385) per month, varying according to the room standard and level of care required. The fees are more than ordinary nursing home services, but less than private hospital services. The initial phase of the service was subsidized by a charity organization. After the subsidies expire, the service will solely rely on fees paid by users. To maintain sustainability, the fees paid by users are adjusted according to market demand and the costs incurred. The service ran a trial in 2006 and was operational by April 2009. The service team conducted an inhouse evaluation of their new service by pre-post study design during the trial run, and improvements 
in outcome measures (including functional status, cognitive status, and caregiver burden) were observed. However, their evaluation study did not include a comparison group. Thus, to provide results that are more valid and to avoid a possible conflict of interest, we, as a third-party, conducted this evaluation study using a quasi-experimental design to examine if the new service was comparable with the usual care option in terms of rehabilitation outcomes. The objective of this study was to evaluate the effectiveness of this new stroke rehabilitation service in terms of rehabilitation outcomes compared with the usual care option.

\section{Materials and methods Study design}

The new service option was a nongovernmental organizationoperated user-pay program providing post-discharge rehabilitation for stroke patients (aged 50 years and older) in a residential care setting for approximately 4 months. At the time of study, this service was operated at a single center. As with other regular services, the aim of rehabilitation was to help patients recover their functional and cognitive status. In addition, the new service highlighted the aim of facilitating clients to return to their home afterwards. This service allows patients more time for recovery after hospital discharge and family caregivers more time to prepare for home care. The actual length of stay varied according to patients' willingness and progress in recovery. The services included: regular case conferences where a multidisciplinary team formulated plans and reviewed progress, physiotherapy, acupuncture, and occupational therapy ( 2 hours per day, 6 days per week), doctor consultations, round-the-clock nursing care, meals designed by a dietitian, counseling for patients and family members, and caregiver training, predischarge home visits and assessments, and social programs and personal care typical of residential care.

A usual care option, ie, a low-charged program providing post-discharge rehabilitation for stroke patients (mainly elderly) in a publicly funded geriatric day hospital, served as the control group. Geriatric day hospitals in Hong Kong are effective for achieving functional recovery in elderly stroke patients when compared with conventional inpatient services. ${ }^{18}$ Owing to the limited capacity of subsidized facilities, patients could only visit the geriatric day hospital twice a week for approximately 3 months (patients could also opt for less). Also, because travelling was involved, visiting a geriatric day hospital more frequently might be exhausting for patients. The rehabilitation programs varied in length according to patients' progress in recovery. The services included: regular case conferences where a multidisciplinary team formulated plans and reviewed progress, physiotherapy and occupational therapy (4-6 hours per day, 2 days per week), doctors' assessments and consultations, lunch designed by a dietitian, predischarge home visits and assessments for selected patients, and optional transportation to the geriatric day hospital at an extra charge.

The differences between the two services included the round-the-clock nursing care and residential care provided by the new service but not the usual care option; the saving of tiring travelling by the new service as compared with usual care; and the home-like environment in the new service but hospital setting in the usual care. In terms of rehabilitation, the new service was similar to the usual care option in that there were approximately 12 hours of physiotherapy and occupational therapy a week. The two services differed in that the new service provided such therapy 6 days a week, but the usual care option squeezed all therapy hours into 2 days. The new service also used more advanced rehabilitation equipment, eg, computer games, than the usual care option.

We used a quasi-experimental design. A randomized controlled trial was not feasible given that the new service was already available and stroke patients were free to choose their service. The intervention group and control group consisted of stroke patients using the new service and the usual service provided by one geriatric day hospital, respectively.

The primary outcome measures were functional and cognitive status as measured by the Chinese version of the Modified Barthel Index (MBI) ${ }^{19,20}$ and Mini-Mental Status Examination (MMSE), ${ }^{21}$ respectively. The MBI score, ranging from 0 to 100 , has good psychometric properties for application with older stroke patients. ${ }^{19,20}$ Higher scores indicate more independent activities of daily living. It is also a common measure used in hospitals in Hong Kong. MMSE scores could range from 0 to 30; this scale has good psychometric properties for application with the elderly, ${ }^{21}$ with higher scores indicating better cognitive status.

Secondary outcome measures included psychosocial status measured by the Chinese version of the Geriatric Depression Scale (GDS) ${ }^{22}$ and the State Self-Esteem Scale (SSES). ${ }^{23,24}$ We also assessed caregiver burden using the Chinese version of the Zarit Burden Interview (ZBI). ${ }^{25,26}$ Depression was measured by the GDS, with higher scores indicating more depressive symptoms; a cutoff point of 8 indicates depression. ${ }^{22}$ Patients' current feelings of selfworth were measured by the SSES, ${ }^{23,24}$ with higher scores indicating greater feelings of self-worth. Psychosocial outcomes were not collected from participants with cognitive 
impairment (MMSE scores below 19). For caregiver burden (ZBI), higher scores indicated greater caregiver burden. ${ }^{25,26}$

For both the intervention and control groups, participants were screened for eligibility and recruited at admission. The patients' caregivers, if any, were also recruited for assessment of caregiver burden as measured by the ZBI. Included were Chinese stroke patients at hospital discharge who had no known communicable disease, were emotionally calm, could understand rehabilitation instructions, were within the 6-month post-stroke period, and were living in the community before stroke onset. To enhance similarity between the intervention and control groups, controls were matched to the intervention group for age, gender, and functional status as measured by MBI. ${ }^{19,20}$ Stroke patients with MBI scores greater than 70 were excluded from the control group unless an intervention participant with a similarly high score was included. We excluded participants with serious medical conditions that would affect outcome measures, such as stroke recurrence within the study period and readmission to hospital around follow-up and failure to be discharged within 1 month.

Participants were recruited from June 2009 to May 2012. Informed consent was sought from all participants and ethical approval was granted by the Chinese University of Hong Kong. Trained research assistants collected participant demographic information and medical history at the beginning of the rehabilitation program (baseline) and assessed their outcome measures. Although the rehabilitation program usually lasted for 3-4 months, the outcome measures were not measured at the end of the rehabilitation program because there is a natural course of recovery for stroke. Instead, a fixed time, ie, 4 months after stroke, was used as the follow-up point to minimize differences arising from the natural progression of health status, regardless of whether participants had completed the program. To collect qualitative feedback about the new service, some caregivers in the intervention group were asked an open-ended question about general comments toward the new service. Since the subsample was not representative, we treated the feedback as informal and supplementary to the main results.

\section{Sample size}

We expected that the full capacity of the service during recruitment would be approximately 165 stroke patients, about $65 \%$ of whom (ie, 107 patients) would meet our eligibility criteria. Since the new service might not be operating at full capacity, fewer than 107 participants from the intervention group might be recruited. In contrast with the limited availability of intervention group participants, we expected the usual capacity for stroke patients at the geriatric day hospital (approximately 500) during the recruitment period. We set a target ratio of 2:1 for control to intervention participants, to achieve sufficient statistical power. Since the sample size was constrained for the intervention group, a post hoc power analysis was conducted to assess the statistical power resulted from the achieved sample size.

\section{Statistical analysis}

We adopted an intention-to-treat analysis. Descriptive statistics were used to summarize participant characteristics and outcomes. Changes in outcome measures at 4-month follow-up compared with baseline were calculated for each participant. Multiple linear regressions were used to compare mean changes in each outcome variable between the two groups. Treatment group was used as an independent variable. An insignificant treatment group effect indicated an insignificant between-group difference. To control for possible differences in age, gender, and baseline outcome measures, these variables were included as independent variables in the multiple linear regression models, in addition to the treatment group. Interactions between treatment group and age, gender, and baseline outcomes were also included. All independent variables entered into the model and insignificant interaction terms would be removed from the model. The proportion of variance explained by treatment group out of the variance unexplained by the remainder of the model (partial $\eta^{2}$ ) was used to report the effect of between-group differences. Statistical Package for the Social Sciences version 20 software (SPSS Inc, Chicago, IL, USA) was used for the analysis and a significance level of $5 \%$ was adopted.

\section{Results}

Sixty and 128 participants were recruited for the intervention and control groups, respectively (response rate, 90.8\%). Fifty intervention participants and 105 control participants completed the 4-month follow-up (attrition rate, 17.6\%). We observed no significant differences in baseline outcome measures between dropout participants and those who completed the follow-up, after controlling for age and gender. Figure 1 shows the study flow.

Post hoc power analysis showed that, with 50 intervention and 105 control participants, our analysis had a power of $82 \%$ to detect a medium effect size (Cohen's $d=0.5$ ) at a $5 \%$ level of significance. In other words, a nonsignificant result for the between-group assessment implied that the differences between control and intervention groups were likely to be small. 
Intervention group

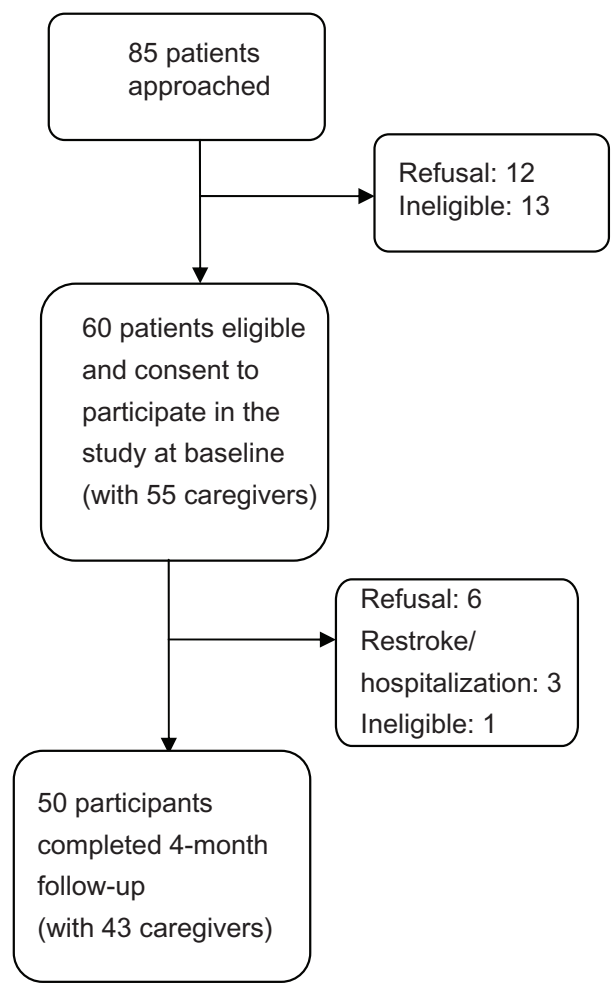

Figure I Flow of study.

At baseline, the mean age ( \pm standard deviation) of intervention participants was $70.0 \pm 11.3$ years and that of controls was $72.7 \pm 10.4$ years. About $43.3 \%$ of intervention participants and $59.4 \%$ of controls were male. Participant characteristics are summarized in Table 1. At baseline, the two groups did not differ significantly in most demographic characteristics, although the intervention group had more female patients $(P=0.040)$ and more patients with higher household income $(P=0.001)$ than the control group. For baseline outcome measures, the two groups did not significantly differ in MMSE $(P=0.951)$, SSES $(P=0.337)$, or ZBI $(P=0.179)$ scores. However, intervention participants had lower MBI scores by 10.1 points (95\% confidence interval [CI $]$ 3.4-16.7, $P=0.003$ ) and higher GDS scores by 1.8 points (95\% CI 0.5-3.1, $P=0.007)$ compared with controls. Differences in baseline outcome measures may have an influence on changes in measures at 4 months. Hence, we controlled for baseline differences by including the baseline outcome measures as independent variables in the multiple linear regression models.

On average, intervention participants utilized the service for a mean of $4.1 \pm 2.9$ months and control participants for $3.2 \pm 1.6$ months. Intervention participants had a significantly longer duration of service by 0.9 months ( $95 \%$ CI $0.1-1.7$ ) compared with controls.

\section{Control group}

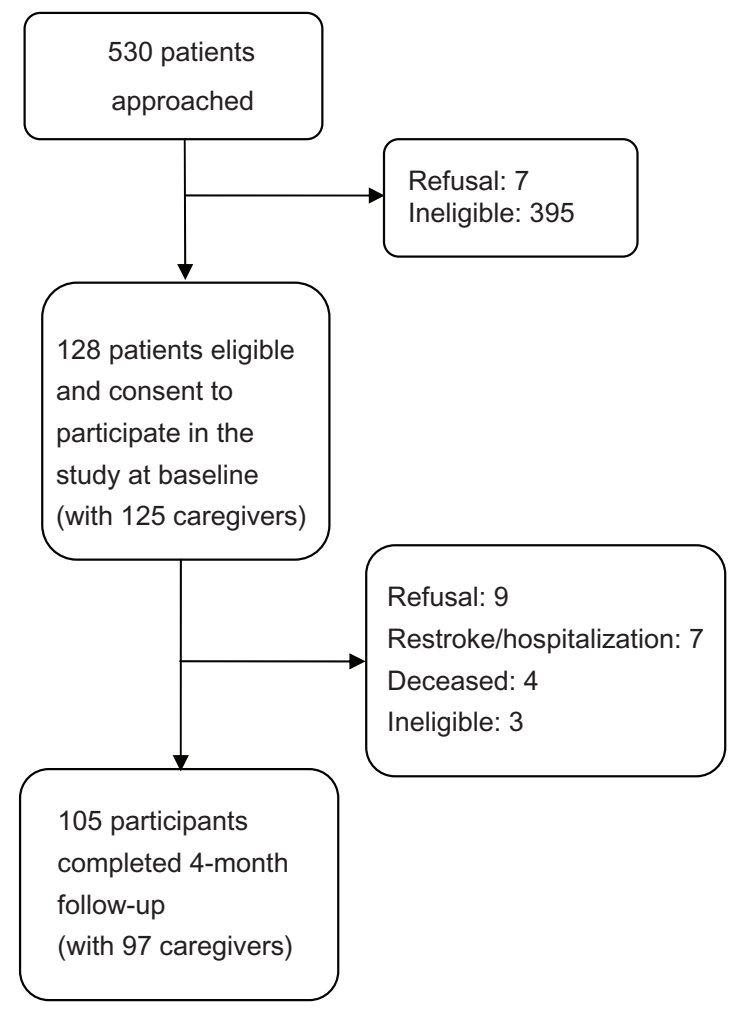

Table 2 shows outcome measure improvements for the two groups. There were insignificant interactions between treatment group and age, gender, and baseline outcomes. Hence, these interaction terms were removed from the multiple linear regression models. At 4-month follow-up, the intervention group had an increased MBI score of 15.3 (95\% CI 10.8-19.8) and an MMSE score of 1.3 (95\% CI 0.4-2.1). By comparison, the control group had an increased MBI score of 13.3 (95\% CI 9.7-16.8) and an MMSE score of 1.1 (95\% CI 0.4-1.9). While there was significant improvement in both functional and cognitive status for both groups, there was no significant between-group difference, as shown by the insignificant treatment group effect (MBI, $P=0.648$; MMSE, $P=0.936$ ) after controlling for age, gender, and baseline measurements. The mean changes in SSES, GDS, and ZBI scores between assessment times are shown in Table 2, and there were no significant improvements within each group between baseline and follow-up, except that the control group had a decreased ZBI score of 3.9 (95\% CI 1.2-6.7). The two groups did not show significant differences for any secondary outcome measure improvements, caregiver burden included, $(P>0.05$, see Table 2$)$ after controlling for age, gender, and baseline measurements. Partial $\eta^{2}$ of the treatment group ranged from $0.005 \%$ to $1.5 \%$ in the five multiple linear regression models, implying 
Table I Characteristics of participants at baseline

\begin{tabular}{|c|c|c|c|}
\hline & $\begin{array}{l}\text { Intervention } \\
\text { group } \\
\end{array}$ & $\begin{array}{l}\text { Control } \\
\text { group }\end{array}$ & $\begin{array}{l}P \text {-value for } \\
\text { baseline }\end{array}$ \\
\hline & $n$ & $\bar{n}$ & \\
\hline \multicolumn{4}{|l|}{ Patients } \\
\hline n & 60 & 128 & \\
\hline Age, year (mean \pm SD) & $70.0 \pm 11.3$ & $72.7 \pm 10.4$ & 0.106 \\
\hline Gender & & & $0.040 *$ \\
\hline Male & $26(43.3 \%)$ & 76 (59.4\%) & \\
\hline Female & 34 (56.7\%) & $52(40.6 \%)$ & \\
\hline Monthly household & & & $0.00 I^{*}$ \\
\hline \multicolumn{4}{|l|}{ income, $\mathrm{HK} \$^{\#}$} \\
\hline$<2000$ & $17(28.3 \%)$ & $26(20.3 \%)$ & \\
\hline 2000-9999 & 7 (11.7\%) & $54(42.2 \%)$ & \\
\hline $10000-14999$ & $5(8.3 \%)$ & $16(12.5 \%)$ & \\
\hline I5000-29999 & 14 (23.3\%) & 20 (I5.6\%) & \\
\hline$\geq 30000$ & II (18.3\%) & $10(7.8 \%)$ & \\
\hline Missing & $6(10.0 \%)$ & $2(1.6 \%)$ & \\
\hline Marital status & & & 0.888 \\
\hline Never married & $\mathrm{I}(\mathrm{I} .7 \%)$ & $3(2.3 \%)$ & \\
\hline Currently married & $39(65.0 \%)$ & $79(61.7 \%)$ & \\
\hline $\begin{array}{l}\text { Separated/divorced/ } \\
\text { widowed }\end{array}$ & 20 (33.3\%) & 46 (35.9\%) & \\
\hline First-ever stroke & & & 0.926 \\
\hline Yes & 49 (8I.7\%) & 103 (80.5\%) & \\
\hline No & II (I8.3\%) & $24(18.8 \%)$ & \\
\hline Missing & - & $\mathrm{I}(0.8 \%)$ & \\
\hline Type of stroke & & & 0.053 \\
\hline Ischemic & 41 (68.3\%) & 103 (80.5\%) & \\
\hline Hemorrhagic & 19 (31.7\%) & $24(18.8 \%)$ & \\
\hline Missing & - & $\mathrm{I}(0.8 \%)$ & \\
\hline $\begin{array}{l}\text { Time from stroke to } \\
\text { rehabilitation, month } \\
\text { (mean, SD) }\end{array}$ & $2.1 \pm 1.1$ & $1.8 \pm 0.9$ & 0.085 \\
\hline $\mathrm{MBI}($ mean, SD) & $41.8 \pm 23.3$ & $51.9 \pm 20.6$ & $0.003 *$ \\
\hline MMSE (mean, SD) & $19.7 \pm 8.2$ & $19.6 \pm 6.5$ & 0.951 \\
\hline GDS (mean, SD) & $8.3 \pm 3.2$ & $6.5 \pm 3.3$ & $0.007^{*}$ \\
\hline SSES (mean, SD) & $72.2 \pm 10.3$ & $69.8 \pm 12.5$ & 0.337 \\
\hline \multicolumn{4}{|l|}{ Caregiver } \\
\hline $\mathrm{n}$ & 55 & 125 & \\
\hline Age, year (mean, SD) & $54.0 \pm 11.8$ & $54.4 \pm 11.6$ & 0.818 \\
\hline Gender & & & 0.542 \\
\hline Male & $13(23.6 \%)$ & $35(28.0 \%)$ & \\
\hline Female & $42(76.4 \%)$ & 90 (72.0\%) & \\
\hline Living with patients & & & 0.494 \\
\hline Yes & $30(54.5 \%)$ & $75(60.0 \%)$ & \\
\hline No & 25 (45.5\%) & 50 (40.0\%) & \\
\hline Relationship with patient & & & 0.838 \\
\hline Spouse & $22(40.0 \%)$ & $5 \mathrm{I}(40.8 \%)$ & \\
\hline Children/children-in-law & $31(56.4 \%)$ & $67(53.6 \%)$ & \\
\hline Others & $2(3.6 \%)$ & $7(5.6 \%)$ & \\
\hline Domestic helper & & & 0.839 \\
\hline Yes & 18 (32.7\%) & 39 (3I.2\%) & \\
\hline No & 37 (67.3\%) & $86(68.8 \%)$ & \\
\hline ZBI (mean, SD) & $32.4(14.9)$ & $35.9(16.7)$ & 0.179 \\
\hline
\end{tabular}

Notes: "HK\$7.8=US\$1; *significant difference at baseline at $5 \%$ level of significance.

Abbreviations: SD, standard deviation; MBI, Modified Barthel Index; MMSE, MiniMental Status Examination; GDS, Geriatric Depression Scale; SSES, State Self-Esteem Scale; ZBI, Zarit Burden Interview. that differences in changes in the outcome measures between the two treatment groups were very small.

A possible confounder, ie, household income, was not included in the multiple linear regression model. This was because about $10 \%$ of intervention participants and $2 \%$ of control participants did not provide this information, and including it would have decreased overall statistical power. Nevertheless, multiple linear regression models were performed including this variable, and the same conclusion that there was no significant between-group differences in changes in outcome measures, was reached. Partial $\eta^{2}$ of the treatment group ranged from $0.005 \%$ to $1.1 \%$ in the five multiple linear regression models, implying differences in changes in the outcome measures between the two treatment groups were very small.

Eleven caregivers in the intervention group were invited to give informal feedback regarding the new service. Eight of them accepted the invitation (16\% of those completed the 4-month follow-up). Among them, three had positive comments, two had negative comments, and three had no comment. Those with positive comments were particularly satisfied with the physiotherapy and occupational therapy as well as the home-like environment provided by the new service. Those with negative comments mentioned the quality of services, particularly services provided by the personal caretakers and the high cost. The changes in caregiver burden (measured by ZBI) did not seem to relate to the informal feedback. Those reporting positive comments had an increased ZBI of 1.0. Those reporting negative comments, having no comment, or refusing to comment had a decreased ZBI score of 2.5, 2.0, and 6.7, respectively.

\section{Discussion}

To ensure a sustainable health care system, particularly for a rapidly aging population, providing alternative user-pay service options should be encouraged. Further, to encourage users to utilize nongovernmental organization or private sector health care services, it is important to show that the alternatives are as good as, if not better than, existing services. This quasi-experimental study showed that a new service option providing rehabilitation in a transitional residential care setting promoted improvements in functional and cognitive status in elderly stroke patients comparable with those of a usual service option (geriatric day hospital rehabilitation). Thus, stroke patients who can afford user-pay/copayment services might consider alternative service options, freeing up public resources for patients with financial constraints. 
Table 2 Changes in outcome measures at 4 months after baseline

\begin{tabular}{llll}
\hline $\begin{array}{l}\text { Outcome measures } \\
\text { (Change defined as score } \\
\text { at } \mathbf{4} \text { months minus score } \\
\text { at baseline) }\end{array}$ & $\begin{array}{l}\text { Intervention group } \\
\text { Mean }(95 \% \mathrm{Cl})\end{array}$ & $\begin{array}{l}\text { Control group } \\
\text { Mean }(95 \% \mathrm{Cl})\end{array}$ & $\begin{array}{l}\text { P-value for } \\
\text { between-group } \\
\text { difference }\end{array}$ \\
\hline MBI & & & $0.648^{\mathrm{a}}$ \\
MMSE & $15.3(10.8-19.8)$ & $13.3(9.7-16.8)$ & $0.936^{\mathrm{a}}$ \\
GDS & $1.3(0.4-2.1)$ & $1.1(0.4-1.9)$ & $0.618^{\mathrm{a}}$ \\
SSES & $-1.0(-2.5$ to 0.4$)$ & $-0.3(-1.1$ to 0.5$)$ & $0.268^{\mathrm{a}}$ \\
ZBI & $2.6(-2.2$ to 7.3$)$ & $1.1(-1.9$ to 4.1$)$ & $0.346^{\mathrm{b}}$ \\
\hline
\end{tabular}

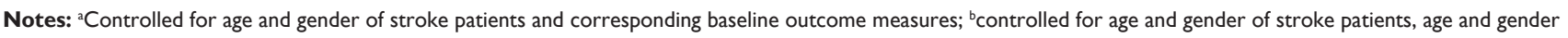
of caregivers, baseline MBI, baseline MMSE, and baseline ZBI.

Abbreviations: $\mathrm{Cl}$, confidence interval; MBI, Modified Barthel Index; MMSE, Mini-Mental Status Examination; GDS, Geriatric Depression Scale; SSES, State Self-Esteem Scale; ZBI, Zarit Burden Interview.

Nevertheless, this new service was targeted for those who could afford user-pay/copayment services as an alternative rather than as a replacement for existing services.

People may expect a new option that charges users more to provide better outcomes than the cheaper option. However, the rationale for providing the user-pay option should not be judged solely in terms of cost-effectiveness. Indeed, apart from the monetary costs, patients have other costs in life, including time and personal experiences. For example, geriatric day hospital-based care involves travelling, which is exceedingly tiring for elderly stroke patients, who must often wait for public transport, and would have difficulty entering and exiting the vehicle. Hence, the self-financing care option, which we have shown to be comparable with the existing public option in terms of rehabilitation outcomes, is worth considering despite its higher fees. In fact, the intervention group's point estimates of the improvements in MBI, MMSE, GDS, and SSES scores were larger than those of the control group, despite the between-group differences not reaching statistical significance. Larger samples might show that the new option brings greater improvements in outcomes than the usual option.

Ideally, service effectiveness should be studied before a service is launched; however, in practice, new services are introduced due to market demands, making randomized controlled trials difficult to apply. Instead, a quasi-experimental design was used. However, our nonrandom assignment of groups may have resulted in selection bias, with overrepresentation of certain participant characteristics in one group (eg, higher income and frailer participants in the intervention group). Nevertheless, when conducting between-groups comparison, the outcome measures at baseline were controlled by including them as independent variables in the multiple linear regression models. Moreover, the assessors were not blinded because the first assessment was on the date of admission at the service venue. This may have potential observer bias.
Hong Kong has a high proportion (about 7\%) of older people staying in old-age homes, more so than in mainland China. ${ }^{27}$ About one third of residents in old-age homes have a history of stroke. ${ }^{28}$ Stroke is a major contributor to disability, and post-stroke dementia is not uncommon. A local longitudinal study showed that deterioration in functional status was a risk factor for institutionalization among people with function and cognitive impairments. ${ }^{29}$ Further, about one third of home-dwelling stroke patients in Hong Kong were reportedly institutionalized at hospital discharge. ${ }^{10} \mathrm{~A}$ study of Chinese stroke patients showed that more sessions of physiotherapy and occupational therapy were related to greater functional improvement within the first 6 months after a stroke (ie, the golden rehabilitation period). ${ }^{30}$ However, in usual care settings, rehabilitation programs are not tailored to stroke patients; indeed, the intensity of these programs might not be able to maximize rehabilitation potential during the golden rehabilitation period. When patients are unable to recover their functional status, their independent living capability is affected, increasing their likelihood of residing in old-age homes for the rest of their lives. However, the new service option, ie, providing transitional residential care together with an onsite rehabilitation program, fills this service gap. While patients can receive usual personal and nursing care at a residential care setting, they aim to be discharged to their own homes. Indeed, this new option provides onsite rehabilitation and traveling is not necessary. However, as the new service uses a user-pay model, which is an unavoidable trend in health care, only patients who can afford it can make use of this service. Since the launch of elderly health care vouchers targeted at primary care, the Hong Kong government has been actively exploring options to facilitate older people's use of user-pay/copayment community services. In September 2013, the government will launch a pilot scheme to provide direct subsidy using a community care service voucher for eligible elderly people, allowing them to 
pay for community services offered by nongovernmental or nonprofit organizations. More elderly people will then be able to afford user-pay/copayment services.

While the users' feelings about the new service could not be reflected by the rehabilitation outcomes, the informal feedback we obtained revealed that service users clearly had expectations toward the quality of services, including staff attitude, environment, meals, and personal care, in addition to the rehabilitation provided by the program. Thus, clients of user-pay services in general may have higher expectations of quality. The intervention group also showed higher study refusal and attrition rates. Because they paid for the service, they may have believed that they did not need to take part in a research study. Hence, service providers should take note of the demands and needs of patients, in addition to rehabilitation outcomes.

To conclude, our study examined the effectiveness of providing onsite rehabilitation care for elderly stroke survivors in a residential setting. Findings at the 4-month follow-up showed that the new service option promoted improvement in rehabilitation outcomes comparable with that of usual care. Partnership with the private sector and nongovernmental organizations is a way to relieve the burden placed on the public health care system. Providing alternative care options using a user-pay model should be encouraged to ensure a sustainable health care system, particularly for the current rapidly aging population. Because some patients who could afford user-pay/copayment services would opt for these alternative options, public resources could then be more available to patients with financial problems. We noted suggestions for improving the alternative service options, highlighting that the quality of the supplementary services is as important as rehabilitation outcomes.

\section{Acknowledgments}

This study was funded by the Hong Kong Jockey Club Charities Trust under the CADENZA Fellowship Programme. The authors would like to acknowledge the nongovernmental organization and the geriatric day hospital for participating in this study.

\section{Disclosure}

The authors report no conflicts of interest in this work.

\section{References}

1. Leung GM, Wong IOL, Chan WS, Choi S, Lo SV. The ecology of health care in Hong Kong. Soc Sci Med. 2005;61:577-590.

2. World Health Organization and Department of Health, Hong Kong. Health Service Delivery Profile. Hong Kong (China). 2012. Available from: http://www.wpro.who.int/health_services/service_delivery_ profile_hong_kong_\%28china\%29.pdf. Accessed June 5, 2013.
3. Hong Kong Hospital Authority. Fees and Charges. 2013. Available from: http://www.ha.org.hk/. Accessed June 5, 2013.

4. Food and Health Bureau of Hong Kong. My Health My Choice: Healthcare Reform Second Stage Consultation Document. 2010. Available from: http://www.myhealthmychoice.gov.hk/pdf/consultation_full_eng. pdf. Accessed June 5, 2013.

5. Hong Kong Hospital Authority. Hospital Authority Statistical Report 2010-2011. 2012. Available from: http://www.ha.org.hk/upload/publication_15/411.pdf. Accessed June 5, 2013.

6. Hong Kong Census and Statistics Department. Table 002: Population by Age Group and Sex. 2013. Available from: http://www.censtatd. gov.hk/showtableexcel2.jsp?tableID=002. Accessed June 5, 2013.

7. Chau PH, Woo J, Goggins WB, et al. Trends of stroke incidence among a Chinese population differ by stroke subtype. Cerebrovasc Dis. 2011;31:138-146.

8. Department of Health, Hong Kong. Age-standardised death rates by leading causes of death, 2001-2011. 2012. Available from: http://www. chp.gov.hk/en/data/4/10/27/339.html. Accessed June 5, 2013.

9. Kwok T, Lo RS, Wong E, Tang WK, Mok V, Wong KS. Quality of life of stroke survivors: a 1-year follow-up study. Arch Phys Med Rehabil. 2006;87:1177-1182.

10. Chan CK, Chan DW, Wong SK. Evaluation of the functional independence for stroke survivors in the community. Asian J Gerontol Geriatr. 2009;4:24-29.

11. Hong Kong Special Administrative Region Government. Hong Kong: The Facts. Public Health. Available from: http://www.gov.hk/en/about/ abouthk/factsheets/docs/public_health.pdf. Accessed June 5, 2013.

12. Björkdahl A, Nilsson AL, Grimby G, Sunnerhagen KS. Does a short period of rehabilitation in the home setting facilitate functioning after stroke? A randomized controlled trial. Clin Rehabil. 2006;20: 1038-1049.

13. Crotty M, Giles LC, Halbert J, Harding J, Miller M. Home versus day rehabilitation: a randomised controlled trial. Age Ageing. 2008;37: 628-633.

14. Forster A, Young J. Community rehabilitation for older people: day hospital or home-based services? Age Ageing. 2011;40:2-4.

15. Stolee P, Hillier LM, Webster F, O'Callaghan C. Stroke care in longterm care facilities in southwestern Ontario. Top Stroke Rehabil. 2006;13:97-108.

16. Leeds L, Meara J, Hobson P. The impact of discharge to a care home on longer term stroke outcomes. Clin Rehabil. 2004;18:924-928.

17. Spruit-van Eijk M, Zuidema SU, Buijck BI, Koopmans RT, Geurts AC. Determinants of rehabilitation outcome in geriatric patients admitted to skilled nursing facilities after stroke: a Dutch multi-centre cohort study. Age Ageing. 2012;41:746-752.

18. Hui E, Lum CM, Woo J, Or KH, Kay RL. Outcomes of elderly stroke patients. Day hospital versus conventional medical management. Stroke. 1995;26:1616-1619.

19. Shah S, Vanclay F, Cooper B. Improving the sensitivity of the Barthel Index for stroke rehabilitation. J Clin Epidemiol. 1989;42: 703-709.

20. Leung SO, Chan CC, Shah S. Development of a Chinese version of the Modified Barthel Index - validity and reliability. Clin Rehabil. 2007;21:912-922.

21. Chiu HFK, Lee HC, Chung WS, Kwong PK. Reliability and validity of the Cantonese version of the Mini-Mental State Examination: a preliminary study. J Hong Kong Coll Psychiatry. 1994;4:25-28.

22. Chiu HF, Lee HC, Wing YK, Kwong PK, Leung CM, Chung DW. Reliability, validity and structure of the Chinese Geriatric Depression Scale in a Hong Kong context: a preliminary report. Singapore Med J. 1994;35:477-480.

23. Heatherton TF, Polivy J. Development and validation of a scale for measuring self-esteem. J Pers Soc Psychol. 1991;60:895-910.

24. Chang AM. Psychosocial nursing intervention to promote selfesteem and functional independence following stroke. Dissertation. Hong Kong, People's Republic of China: The Chinese University of Hong Kong; 1999.

25. Zarit SH, Reever KE, Bach-Peterson J. Relatives of the impaired elderly: correlates of feelings of burden. Gerontologist. 1980;20: 649-655. 
26. Chan TS, Lam LC, Chiu HF. Validation of the Chinese version of the Zarit Burden Interview. Hong Kong J Psychiatry. 2005;15:9-13.

27. Chau PH, Wong M, Woo J. Challenge to long-term care for the elderly: cold-weather impacts institutional population more than communitydwelling population. J Am Med Dir Assoc. 2012;13:788-793.

28. Woo J, Chau PH. Aging in Hong Kong: the institutional population. J Am Med Dir Assoc. 2009;10:478-485.
29. Chau PH, Woo J, Kwok T, Chan F, Hui E, Chan KC. Usage of community services and domestic helpers predicted institutionalization of the elders having functional or cognitive impairments: a 12-month longitudinal study in Hong Kong. J Am Med Dir Assoc. 2012;13:169-175.

30. Huang HC, Chung KC, Lai DC, Sung SF. The impact of timing and dose of rehabilitation delivery on functional recovery of stroke patients. J Chin Med Assoc. 2009;72:257-264.

\section{Publish your work in this journal}

Clinical Interventions in Aging is an international, peer-reviewed journal focusing on evidence-based reports on the value or lack thereof of treatments intended to prevent or delay the onset of maladaptive correlates of aging in human beings. This journal is indexed on PubMed Central, MedLine, the American Chemical Society's 'Chemical Abstracts Ser-

\section{Dovepress}

vice' (CAS), Scopus and the Elsevier Bibliographic databases. The manuscript management system is completely online and includes a very quick and fair peer-review system, which is all easy to use. Visit $\mathrm{http}: / / \mathrm{www}$.dovepress.com/testimonials.php to read real quotes from published authors.

Submit your manuscript here: http://www.dovepress.com/clinical-interventions-in-aging-journal 